\title{
Psychotherapeutic Work in Palliative Care
}

\author{
Jan Gramm $^{\mathrm{a}} \quad$ Manuel Trachsel $^{\mathrm{b}} \quad$ Daniel Berthold $^{\mathrm{a}}$

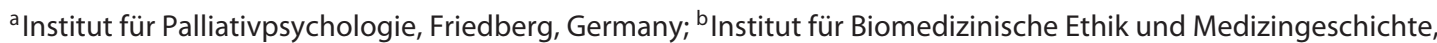 \\ Universität Zürich, Zurich, Switzerland
}

\section{Keywords}

Palliative care End of life - Terminally ill patients .

Psychological intervention P Psychotherapy

\begin{abstract}
In palliative care, multi-professional teams work to improve and maintain the quality of life of terminally ill patients and their families. In this field, clinical psychologists and psychotherapists take on a broad variety of tasks that range from preventive and supportive to psychotherapeutic work. Even if the provision of palliative care frequently does not yet offer appropriate need-based care by psychologists and psychotherapists, developments to that effect are clearly noticeable. The aim of the present article is to give an overview of palliative care as an area of application for psychological and psychotherapeutic interventions. After depicting relevant features of palliative care, characteristic topics, strains, and mental disorders in palliative care will be briefly delineated. Finally, an overview of psychological and psychotherapeutic interventions for palliative care will be presented.
\end{abstract}

(c) 2020 S. Karger AG, Basel
Psychotherapeutisches Arbeiten in Palliative Care

\section{Schlüsselwörter}

Palliative Care · Lebensende · Unheilbar erkrankte

Patienten · Psychologische Intervention · Psychotherapie

\section{Zusammenfassung}

In Palliative Care arbeiten multiprofessionell zusammengesetzte Teams für die Verbesserung oder Erhaltung der Lebensqualität von schwerstkranken Patienten und ihren Familien. Klinischen Psychologen und approbierten Psychotherapeuten kommt in diesem Feld ein vielfältiges Spektrum von Aufgaben zu, das von der präventiven und supportiven Arbeit bis hin zum psychotherapeutischen Wirken im engeren Sinne reicht. Auch wenn die Palliativversorgung bislang vielerorts noch keine bedarfsgerechte Begleitung durch Psychologen und Psychotherapeuten leistet, sind entsprechende Entwicklungen deutlich festzustellen. Ziel des vorliegenden Beitrags ist es, einen Überblick über Palliative Care als Anwendungsfeld psychologischer und psychotherapeutischer Interventionen zu geben. Nach einer Skizzierung der relevanten Grundzüge von Palliative Care erfolgt eine Darstellung psycho- 
logischer und psychotherapeutischer Themen, subdiagnostischer Befunde sowie psychischer Störungen in der Palliativversorgung. Schließlich soll eine Übersicht psychologischer und psychotherapeutischer Interventionen in Palliative Care gegeben werden.

(c) 2020 S. Karger AG, Basel

Death speaks: There was a merchant in Baghdad who sent his servant to market to buy provisions and in a little while the servant came back, white and trembling, and said, Master, just now when I was in the marketplace I was jostled by a woman in the crowd and when I turned I saw it was Death that jostled me. She looked at me and made a threatening gesture; now, lend me your horse, and I will ride away from this city and avoid my fate. I will go to Samarra and there Death will not find me. The merchant lent him his horse, and the servant mounted it, and he dug his spurs in its flanks and as fast as the horse could gallop he went. Then the merchant went down to the market-place and he saw me standing in the crowd and he came to me and said, Why did you make a threatening gesture to my servant when you saw him this morning? That was not a threatening gesture, I said, it was only a start of surprise. I was astonished to see him in Baghdad, for I had an appointment with him tonight in Samarra. William Somerset Maugham [1933]

\section{Introduction}

Maugham's parable might well describe the relationship of modern medicine to death: although chronic progressive illnesses have always been associated with comorbidity and a steady deterioration of the general condition and many of these illnesses ultimately end in death, attention is directed not to death, but to the putative possibilities for healing. This avoidance strategy ultimately entails useless treatments (medical futility) [Schneiderman et al., 1990; Merano, 2003; Becker and Blum, 2004]. As a result, not only are patients and relatives largely unprepared, but so are health-care providers.

Palliative care, by not tabooing critical issues in the trajectories of incurable illnesses, but explicitly addressing them, gives patients and their relatives the opportunity to adjust to the time remaining and the circumstances at the end of life. But above all, the palliative care team can formulate therapeutic goals that can be pursued in view of the medical situation (indication), according to the patient's wishes and, if appropriate, taking into account the requirements of the relatives. In contrast to mainstream medicine that is oriented to somatic deficits, therapeutic goals are therefore not defined solely with regard to the illness process. Rather, a contextualization takes place, so that in addition to the effectiveness of a treatment, the question of its meaningfulness always comes into focus [Sauer and Weiske, in press], e.g., when the determination of a comatose patient's presumed in- tention results from the fact that the patient had always refused artificial feeding.

With regard to the question of meaningfulness, change-oriented therapeutic goals are supplemented by those that involve acceptance of what cannot be changed, not as admission of failure, but as a realistic option. The palliative movement ultimately brought into medicine what was introduced into psychotherapeutic care through the third wave of behavioral therapy [Heidenreich et al., 2007; Heidenreich and Michalak, 2013].

Psychologists and psychotherapists in palliative care have an extremely diverse range of tasks that include guiding caregiver teams, teaching and training, research, and public relations [Berufsverband Deutscher Psychologinnen und Psychologen (BDP), 2016]. The present contribution focuses on clinical-psychological work with patients and their relatives.

\section{Parameters for Psychological and Psychotherapeutic Work}

\subsection{Palliative Care as a Multi-Professional Field}

The World Health Organization defines palliative care as an approach "that improves the quality of life of patients and their families facing the problems associated with life-threatening illness, through the prevention and relief of suffering by means of early identification and impeccable assessment and treatment of pain and other problems, physical, psychosocial and spiritual" [World Health Organization (WHO), 2002]. This definition has a number of implications that characterize the conception of palliative care: at the center is the claim of biopsycho-socio-spiritual treatment that necessitates a multi-professional care setting. With quality of life as the paramount therapeutic goal, subjective experience has a special significance: "Pain is what the patient says it is." The explicit identification of loved ones as (co-)affected persons underlines the genuinely systemic vision of the field: patients are not understood as independent individuals, but always as integrated into interactive systems of family and practitioner.

\subsection{Job Description of Palliative Psychology}

Despite the aspiration to multi-professional care, in German speaking countries the involvement of psychologists and psychotherapists in palliative and hospice care has not yet been clearly regulated. There are no clear legal requirements for training. The Psychology Section of the Deutsche Gesellschaft für Palliativmedizin (DGP) came up with the job description of "Palliative Psychology" that was included by the Association of German Professional Psychologists (Berufsverband Deutscher Psychologinnen und Psychologen, BDP) in the catalog of 
psychological occupations [Psychology Section of the DGP, 2016; BDP, 2016]. The job description itemizes what psychologists do in palliative care - regardless of whether they have an additional psychotherapeutic qualification or license. Palliative psychology is thus a branch of health psychology and clinical psychology, whereby working with patients and relatives is an important, but not the only, function of psychologists in palliative care [Münch et al., 2016].

\subsection{Palliative Patient Clientele}

Palliative patients differ in many respects from the "classical" patient clientele of psychotherapeutic care. Initial contact usually takes place when there is already a superficial palliative care or hospice situation, i.e., when there is a life-limiting progressive illness. Besides cancer, these include cardiovascular diseases (e.g., heart failure), disease of the kidneys or liver, pulmonary diseases (e.g., COPD), neurological diseases (e.g., amyotrophic lateral sclerosis, dementia), metabolic diseases (e.g., diabetes mellitus), infectious diseases (e.g., AIDS), or age-related multimorbidity ("frailty syndrome").

Psychologists and psychotherapists who treat seriously physically ill patients therefore require knowledge about specific illness progressions and the associated challenges for prognosis and treatment. There is thus a big difference between the mostly steady progression of end-stage cancer and the typically strongly oscillating progression of heart illness, which makes it difficult to judge whether a patient will recover from a crisis or whether the point has been reached after which it is better to reconcile oneself with death [Bausewein, 2005]. In palliative situations, common physical symptoms that psychologists and psychotherapists should be aware of include pain, weakness, dyspnea, nausea, constipation, fatigue, sleep disorders, confusion, and loss of appetite [see for example Trachsel and Maercker, 2016].

\subsection{The Palliative Setting}

Palliative illness progressions are associated with high patient vulnerability. For psychological and psychotherapeutic work with the dying, this means that the following conditions must be considered:

- The patient feels different from day to day, unpredictably, so that much more flexible treatment is necessary than the usual 50-minute therapeutic session.

- Limited or no mobility, so that in the outpatient setting usually only home visits are possible.

- Limited availability of relatives providing care, so that they too find it difficult to visit a psychotherapeutic practice.

- Often a limited concentration span or reduced vigilance, so that a high degree of flexibility in scheduling is required.

Psychotherapeutic Work in Palliative
- Frequently impaired speech (due to weakness, dyspnea, or aphasia in cerebral metastases, or neurological disorders).

- Limited (life-)time, so that the psychological and psychotherapeutic work is subject to time pressure.

It follows from the last point that a session - despite the limitations mentioned - can also last two hours or more, for example, when working with both the patient and the relatives, first separately and then together. A therapeutic alliance in the classical sense usually cannot be established because of the limited number of contacts between therapist and patient. Instead, within a short space of time - often in the first few minutes of the first and perhaps only session - the encounter must be deep enough to identify and work on the essential topics.

The particular circumstances of the palliative setting are reflected in the finding that manualized cognitive behavioral therapy for palliative patients proved to be scarcely feasible because, due to their severe physical impairment, only $31 \%$ of patients were able to attend at least eight out of a total of twelve therapy sessions [Serfaty et al., 2019].

\section{Psychological and Psychotherapeutic Topics, Subdiagnostic Findings, and Mental Disorders}

\subsection{Psychological and Psychotherapeutic Topics}

3.1.1. Patients

Aside from their physical symptoms, palliative patients often endure a wide range of psychological and psychotherapeutic issues during their illness, in which emotions such as sorrow, dejection, despair, anxiety, fear, insecurity, and loneliness are closely associated [Block, 2006].

Among the major issues in palliative care are imminent decisions such as treatment options or further care. Sanctioning of feelings and cognitions is a no less significant topic. This often involves the desire to break the emotional downward spiral, which, however, usually has the opposite effect: increasing alienation of family members because of the constrained feelings and cognitions. The question of the right approach to the subject of "dying" in the family is also frequently raised. Additional frequent subjects of psychological and psychotherapeutic sessions in palliative care include demoralization, bitterness, loss of a sense of meaning in life, feeling overwhelmed, helplessness, hopelessness, loss of autonomy, cognitive impairment and concentration disorders, sleep disorders, mood swings, changes in body image, guilt, feeling useless, experience of isolation, loss of dignity, shame, the feeling of being just a burden, and the desire to die [Trachsel and Maercker, 2016]. But there is also the need to grapple with issues experienced by the dying person and relatives as resource- 
enhancing, such as taking stock of one's life, expressing gratitude, taking care of final matters, the desire for reconciliation, and finding inner peace. A meta-synthesis of 35 qualitative studies found four topics that confront patients with terminal cancer: (1) the catastrophic interruption of one's previous life; (2) life as a "cancer patient," with all the impairments related to both the disease and the treatment, associated emotions such as anxiety or guilt, and effects on social life; (3) the experience of liminality, which is not shared by the healthy social environment - in ethnology, a threshold state between an abandoned old order and a new one that has not yet been reached -, and (4) holding on to life [Willig and Wirth, 2018].

\subsubsection{Relatives}

Relatives of extremely ill people are often heavily burdened in the dual role of helping and being affected themselves. Relatives who provide care are particularly burdened by the continuous need for their presence, bearing direct witness to suffering, transitions from hospital to home care, and physical demands [Kern et al., 2009]. They confront many challenges that can be psychologically very stressful, such as concern for the well-being of the patient, organization and management of treatments and support services, fear of the future, disturbed sleep, saying good-bye, making decisions, and uncertainty about the further progression of the illness.

Family roles also change, social contacts are reduced, or substantial financial burdens arise. Thus, the illness may become the "organizing principle" in the family [Kröger et al., 2002], for example if the family's weekly planning must be adjusted because of appointments for treatment. It should also be borne in mind that, in addition to a medical history, the affected families also have a treatment history, which is often associated with demeaning experiences.

\subsection{Subdiagnostic Findings}

Psychological symptoms that do not meet diagnostic criteria are much more common in oncological and palliative patients than in the general population [Mitchell et al., 2011]. Various terms have become established in this context, such as subdiagnostic, subsyndromal, subcategorial, subclinical, and subliminal [Röhrle et al., 2008]. The transition from a normal psychological reaction to one that qualifies as a disorder is not always clearly definable and requires precise differentiation. Nonetheless, the need for psychological or psychotherapeutic support has to be assessed: it may be necessary to provide psychological support to patients and relatives, even though their behavior may seem quite appropriate in view of the palliative situation. In palliative care, the question of whether treatment is suitable should be attached greater importance than whether there is a disorder.

\section{Example: Demoralization}

Demoralization goes beyond the feeling of dejection but does not meet the diagnostic criteria for a mental disorder; nevertheless, it merits psychological treatment. It occurs in clinically relevant form in approximately 13$18 \%$ of all advanced oncology patients [Robinson et al., 2015; Mehnert et al., 2011]. Demoralization is defined by Clarke and Kissane [2002] as:

- affective symptoms of existential despair such as hopelessness, loss of meaning and purpose in life;

- cognitive attitudes characterized by pessimism, helplessness, sense of being trapped, of personal failure, and the lack of a worthwhile future;

- lack of drive and the motivation to cope with the situation differently;

- characteristics of social alienation or isolation as well as lack of support;

- fluctuation in emotional intensity;

- no primary major depression or other mental disorder. While depression is essentially characterized by the general loss of pleasure, enjoyment, and interest, in demoralization there is a loss of a sense of the meaning of life and of hope, as well as of anticipatory pleasure, although enjoyment is retained in the present moment [Robinson et al., 2015]. While the cause of depression cannot always be clearly determined, there is a clear correlation between demoralization and physical symptoms that limit activity (fatigue, immobility, dyspnea, lack of concentration). Severe demoralization is highly correlated with depression, anxiety, and the desire to die [Mehnert et al., 2011]. There is a negative correlation between quality of life and a sense that life is meaningful [Robinson et al., 2015]. This suggests a particular indication for interventions that contribute to the quality of life and a sense of purpose.

\subsection{Mental Disorders}

\subsubsection{Patients}

If one looks for research findings about the prevalence of mental disorders, the considerable range of incidence is striking [Mitchell et al., 2011]. One reason is probably the difficulty in clearly identifying disorders, since the symptoms are partly due to the somatic illness itself or its treatment [Endicott, 1984; Miller and Massie, 2015]. The psychiatric model is only of limited use for psychological symptoms, for example if characteristic symptoms of depression occur frequently in palliative patients and require treatment but do not necessarily indicate underlying depression. Caution should therefore be exercised with regard to whether something should be designated a disorder and whether treatment is indicated.

An example of this is the wish to hasten death, which is expressed frequently by palliative patients, but usually cannot be understood as suicidal ideation and therefore 
is not evidence of depression [Block, 2000; MonforteRoyo et al., 2012]. Therefore, it is meaningful in practice to distinguish between the wish to die and the will to die [Ohnsorge et al., 2014].

But if psychological symptoms that fulfill the diagnostic criteria for a mental disorder are present, they can - in close consultation with the patient - also be treated by disorder specific interventions. Palliative care does not mean that no interventions with curative intentions should be made beyond the palliative approach, if that appears promising [Ferris et al., 2002]. In all kinds of mental disorders at the end of life, such as depressive disorders, anxiety, or obsessive-compulsive disorders, therapists perform either (psycho-)therapeutic treatment according to the applicable guidelines (for unipolar depression, see e.g., Leitlinienprogramm Onkologie [Deutsche Krebsgesellschaft, Deutsche Krebshilfe, AWMF, 2015]) or a therapeutic intervention adapted to the patient's endof-life situation. There is often not enough time left for extended disorder-specific psychotherapies with patients at the end of life. Shorter supportive approaches are better suited for this purpose. Some pharmacological options are also effective more quickly. For example, in a depressive episode at the end of life, when it is inadvisable to wait for two to six weeks until classical antidepressants take effect, the use of a psychostimulant (methylphenidate or modafinil) or ketamine might be offered [see, for example, Macleod, 1998; Andrade, 2017].

Three examples of challenges for palliative patients with specific mental disorders are outlined below.

\section{Example 1: Personality Disorders}

Regardless of whether psychological symptoms exist with or without meeting the diagnostic criteria for a mental disorder, professionals in palliative care are often confronted with patients who have a preexisting personality disorder or accentuated personality traits. Since hardly any psychologists or psychotherapists are integrated into outpatient palliative care and hospices, such patients, who are often perceived and described as "difficult," must be assumed to be generally underserved. Patients with personality disorders or accentuated personality traits in palliative care place an increased burden on caregivers. For example, a patient with a high need for care and a slowly progressing terminal illness, such as amyotrophic lateral sclerosis, and who suffers from an obsessive-compulsive personality disorder, will be a great challenge to the nursing team.

\section{Example 2: Anorexia Nervosa}

Anorexia nervosa is characterized by deliberate selfinduced or maintained weight loss. Despite years of competent treatment, including disorder-specific psychotherapy and force-feeding, there may come a point at which further therapeutic treatment promises little or no benefit. Trachsel et al. [2016] describe the following patient:

"19-year-old Lisa S. [...] is so severely malnourished due to anorexia nervosa and the resulting drastic weight loss that it cannot be ruled out from a medical point of view that her life is in acute danger. Yet the patient firmly rejects further therapeutic measures and thus opposes the wishes of her parents and the recommendation of the treating specialists" [Trachsel et al., 2016, pp. 171-173].

This patient is thus seriously underweight, is no longer motivated to undergo treatment, and has reached the end of her life. This is undoubtedly a palliative situation due to a mental disorder, although the dying process in this case is in principle reversible and there is no explicit desire to die. Yet due to her disordered body image, the patient has a deep conviction that she is (still) not slim enough.

Therefore, Lisa S. poses the following ethical challenges for the treating professionals:

"On the one hand, there must be an assessment of the patient's ability to give consent and, in any case, the greatest possible respect for her autonomy must be ensured; on the other hand, there is the moral duty of professionals to safeguard the patient's life and to intervene, especially if there is doubt as to her ability to give consent" [Trachsel et al., 2016, p. 173].

\section{Example 3: Psychosis or Delirium}

If there is preexisting psychosis or delirium, an evaluation of the patient's ability to give consent is necessary if there are any doubts as to whether a patient is capable of deciding for or against a treatment option [Trachsel et al., 2014a]. If there is a valid advance directive and the patient has lost the ability to give consent to a particular medical option (e.g., a proposed intervention), the patient's advance directive comes into effect, provided its content applies to the given situation. In this case, a valid living will must be strictly adhered to by the treatment team, although there is always some margin of discretion depending on the formulations used [Trachsel et al., 2014b].

An advance directive is valid, however, only if the patient was in a condition to consent to it when it was authored. If this was not confirmed by a doctor at the time that the directive was written, it may be difficult to retrospectively assess whether the patient's consent was actually given. Retrospective assessment is especially challenging for patients with preexisting conditions, which often involve suspension of the ability to give consent. This may apply, for example, to patients with a history of psychosis or delirium. If there is a clear indication that a patient was in a psychotic state when the advance directive was authored, that circumstance may serve as an argument for the invalidity of the advance directive. 


\subsubsection{Relatives}

The extent of morbidity in caregiving relatives has been shown in recent studies to be higher than previous research had reported [Grande et al., 2018]. Preisler and Goerling [2016] show that mental distress is often more prevalent in the relatives than in the patients themselves. Here, we describe anxiety disorders, depression, and adjustment disorders.

\section{Example: Complicated Grief}

Grief relates to complicated grief as dejection relates to depression. Although grief is a natural reaction to loss, difficult grief trajectories and complicated grief may develop. Complicated grief is an independent psychological entity [Prigerson et al., 1996; Znoj, 2016], which is why the WHO, in the new version of the International Classification of Diseases (ICD), provides a specific diagnosis ("Prolonged Grief Disorder"). In contrast to a depressive episode, the mood of a person in such grief fluctuates. Joy can be felt both at the moment and when certain events occur; selfesteem is intact; a desire to hasten death may occur (but not suicidal ideation) [Block, 2006; Strada, 2009]. A thorough differential diagnosis has direct effects on therapy, since grief that rises to the level of a disorder cannot be treated like depression. It requires specifically developed interventions such as family focused grief therapy [Kissane et al., 2006]. In contrast to depression, the use of antidepressants is indicated neither for grief nor for demoralization.

It should be mentioned that grief (mourning) occurs not only after death by relatives, but already in the palliative care phase, by both relatives ("anticipated grief") and patients themselves ("preparatory grief") [Strada, 2009]. Anticipated grief can be expressed like grief after a loss, for example through pain of separation, helplessness and hopelessness, feelings of being overwhelmed, or numb [Znoj, 2016].

\section{Psychological and Psychotherapeutic Interventions}

\subsection{A Model of Palliative Psychological Work}

Berthold and Gramm [2019] describe a model for palliative psychological work with patients and relatives that has five intervention fields (see also Fig. 1).

1. Clarification and information are provided in psychological counseling.

2. Psychological guidance (during the process) covers the three topics of coping, decision-making, and facilitation.

3. Psychological treatment may be necessary as an extension of the topic of coping with subdiagnostic findings. Psychotherapeutic or psychiatric (co-)treatment becomes necessary if there is a mental disorder.

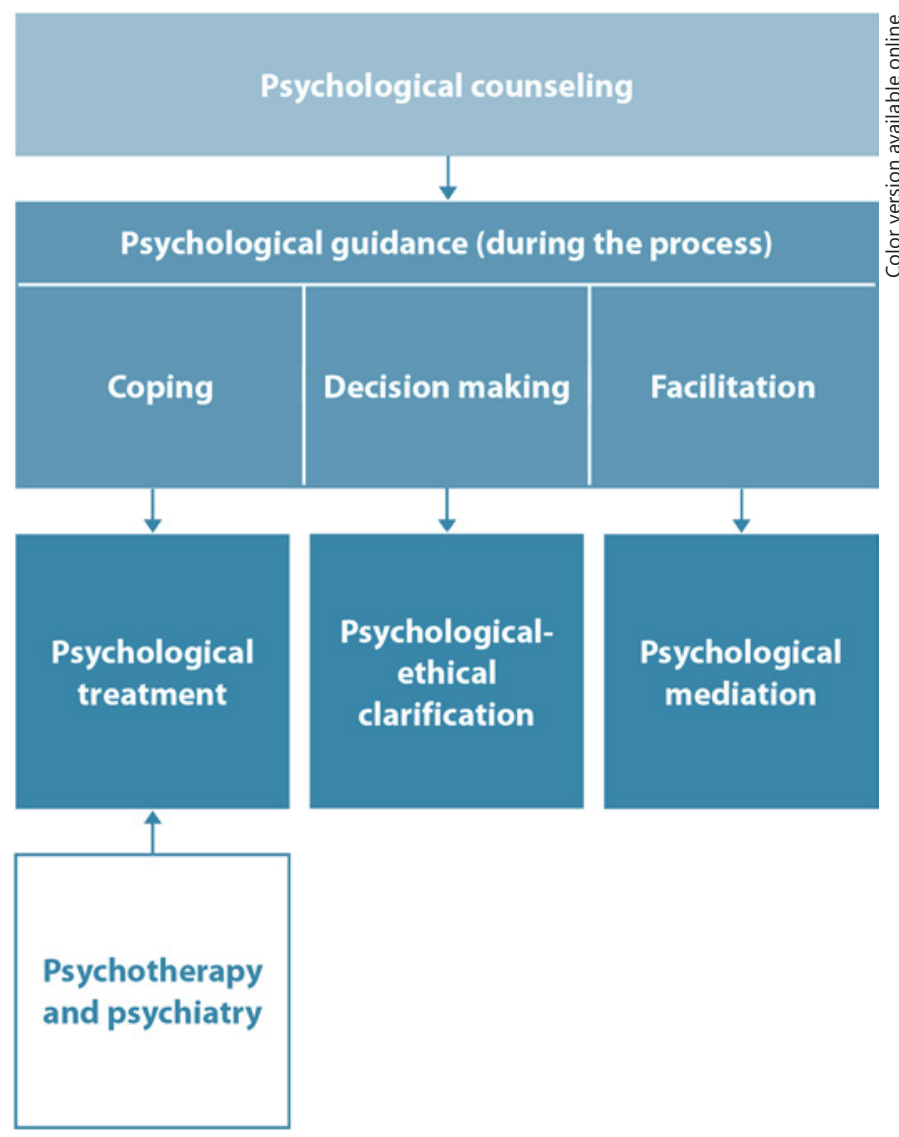

Fig. 1. Intervention fields of palliative psychological work with patients and relatives.

4. Psychological-ethical clarification extends the topic of decision-making if there is a normative conflict, by making explicit and clarifying intra- and interpersonal aspects of decision making (such as feelings of guilt, family or team dynamics). Psychological-ethical clarification serves here as a precursor to clinical ethics counseling.

5. Psychological mediation may be necessary as an extension of the topic of communication when there are serious conflicts.

\subsection{Transfer of Psychotherapeutic Interventions}

If psychotherapeutic interventions are used, they are rarely directed at the psychotherapeutic treatment of psychopathological disorders. In most cases, the primary concern is reducing stressful psychological and somatic symptoms that have a psychogenic component because of the palliative condition [Mehnert, 2015; Münch et al., 2015].

The potential of psychotherapeutic approaches becomes significant at the end of life, however, insofar as such strategies and techniques, as well as their general concepts and basic attitudes, can be transferred and used effectively in an adapted form [Berthold et al., 2017]. A 
transfer from psychotherapeutic interventions to palliative care can therefore be assumed.

Systemic family therapy approaches are of note here. Some that can be very helpful is the genogram, which provides a visual representation of the family's composition [Deutsche Gesellschaft für Palliativmedizin, 2016], and the family conference on the topic of "dying" to balance different needs, to mediate in conflicts, or for further planning of treatment and care to provide psychological support and treatment.

Against this background of high stress, relaxation techniques and imagination techniques are often used. Hypnotherapy for symptom control of pain, respiratory distress, nausea, vomiting, loss of appetite, itching, or insomnia, as well as for psychosocial and spiritual guidance, also promises good results [Schulze, 2013].

Mindfulness-based approaches are especially relevant in palliative care, since patients who repeatedly "reach the limits of what is feasible and planable" can be supported in devoting "attention to the realization and change of processes of inner experience" [Schulz-Kindermann et al., 2013, p. 148].

Similarly, existential-humanistic approaches can be used meaningfully insofar as patients are not only intensely focused on existential issues, but these also cause them significant stress and trigger existential fears [Trachsel and Noyon, 2017]. Methods from existential-humanistic psychotherapy are suitable here, such as those developed on the basis of continental existential philosophy and Anglo-American humanistic psychology by representatives such as James Bugenthal, Rollo May, and Irvin D. Yalom [Schneider and Krug, 2010].

\subsection{Specific Interventions for Work with Palliative Patients}

4.3.1. Meaning-Centered Psychotherapy

One form of existential psychotherapy that, unlike the existential-humanistic psychotherapy described above, focuses on a specific existential issue, is meaning-centered psychotherapy [Breitbart et al., 2012]. Based on Viktor Frankl's logotherapy, Breitbart developed interventions aimed at finding significance and meaning in the face of death. Frankl had recognized "that we no longer simply ask about the meaning of life, but that we experience ourselves as the respondents, as those to whom life asks questions daily and hourly" [Frankl, 2008, p. 125]. Through this reversal of perspective, the person becomes an actor again, even in adverse circumstances, because "Life ultimately means nothing else but taking the responsibility to find the right answer to its questions and to fulfill the tasks which it constantly sets for each individual" [Frankl, 2008, p. 125]. The potential of this therapeutic approach for people who find themselves in an existentially threatening situation is obvious.

Psychotherapeutic Work in Palliative

Care
Meaning-Centered Group Psychotherapy (MCGP) provides a framework in which (oncology) patients together grapple with questions of meaningfulness, inner peace, and purpose in their lives, in the context of their illness. Various topics are explored in eight sessions of psychoeducation, group discussion, and exercises: (1) concepts and sources of meaning; (2) cancer and meaning; (3) historical sources of meaning (legacy: past); (4) historical sources of meaning (legacy: present and future); (5) attitudinal sources of meaning (encountering the limits of life); (6) creative sources of meaning and assumption of responsibility; (7) experiental sources of meaning (nature, art, humor); (8) concluding session (transitions) [Breitbart et al., 2004, 2010].

Since conducting group sessions with palliative patients proved difficult, Individual Meaning-Centered Psychotherapy (IMCP) was developed [Breitbart et al., 2012, 2018]. The topics of the MCGP are developed in seven individual sessions.

\subsubsection{Cognitive-Existential Group Psychotherapy}

Another form of existential psychotherapy for the palliative care context is cognitive-existential group psychotherapy which was developed primarily for breast cancer patients [e.g., Kissane et al., 2003]. This is manualized group therapy for six to eight patients over 20 weekly sessions which is run by two psychotherapists (at least one woman) and pursues the following six goals: (1) promoting a supportive environment; (2) facilitating grief over losses; (3) reframing negative thoughts; (4) enhancing problem solving and coping; (5) fostering hope; and (6) examining priorities for the future. Key topics of the group sessions include: "the threat of death; fear of recurrence; living with uncertainty; understanding treatment with chemotherapy, radiotherapy and hormones; the doctor-patient relationship; body- and self-image; sexuality; surgical reconstruction; relationship with partner, friends and family; and life style and future goals" [Kissane et al., 2003, p. 535]. The method is basically tailored to the needs of breast cancer patients and was empirically best investigated in that context. The approach can, however, be applied to other groups of patients.

\subsubsection{Dignity Therapy}

Since one of the most frequently cited reasons among palliative patients for the desire to die prematurely is the loss of dignity, a working group led by Harvey Max Chochinov created an empirically based Dignity Model, which is divided into three areas: (1) illness-related concerns, (2) social dignity inventory (social aspects), and (3) dignity-conserving repertoire (psychological aspects) [Chochinov, 2002]. Dignity-centered therapy was developed in order to strengthen the psychological aspects [Chochinov et al., 2005]. Using a questionnaire, an inter- 
view is conducted with the patient in which the essence of the personality is expressed (e.g., "When did you feel most alive?") and wishes and concerns for relatives are recorded ("What have you learned about life that you would want to pass along to others?"). The tape-recorded conversation is transcribed, edited, read to the patient, and modified if necessary. After its completion, patients receive a document which they can then pass along to their loved ones or leave behind. In addition to the resource-oriented view of oneself, generativity is another important factor. The therapist takes a systemic position, having to keep an eye not only on the narrator but also on those to whom the document is addressed. Dignity therapy has been adapted to different applications and has been widely evaluated scientifically [Martínez et al., 2017]. A detailed manual is also available in book form in German [Chochinov, 2017].

\subsubsection{Managing Cancer and Living Meaningfully}

Managing Cancer and Living Meaningfully (CALM) is a manualized, semi-structured brief individual psychotherapy developed by the research group around Gary Rodin for people with advanced illness to reduce stress and promote personal growth [Lo et al., 2014]. Therapeutic support for affect regulation, attachment security, and mentalizing focuses on four areas: (1) symptom management and communication with health-care providers; (2) changes in self and relations with close others; (3) sense of meaning and purpose; (4) the future and mortality. CALM gives patients the security to confront their fears, to be seen as vulnerable, and to face the challenges of progressive illness.

\subsection{Specific Interventions for Work with Relatives of Palliative Patients}

The needs and burdens of relatives, and therefore also therapeutic topics affecting them, sometimes differ considerably from those of the patients themselves. Intervention approaches have therefore been developed for this client group which usually include caregiving and financial aspects and were designed for a group setting. Interventions associated with palliative care when there is complicated grief are not specifically addressed here.

\subsubsection{Short-Term Group Intervention for Informal Caregivers}

In the short-term group intervention for informal caregivers [Harding et al., 2002], six group sessions offer a combination of patient-related psychoeducation with exchange and social support, including information on financial support, care, aromatherapy, or guidance on self-care.

\subsubsection{Training for Family Caregivers}

Training for family caregivers (Caregiving at Life's End) [Kwak et al., 2007] comprises five meetings to share experiences of caregiving and to discuss information about practical matters (finances, legal matters, work) and to encourage the acceptance of mortality, as well as finding meaning, and grief.

\subsubsection{Support Program for Relatives}

The support program for relatives [Henriksson and Andershed, 2007] provides six sessions of general information on palliative care, nutrition, practical matters, crisis management, physical and occupational therapy, as well as existential questions and the relatives' own resources.

\subsubsection{Psychoeducational Intervention for Family} Caregivers

The psychoeducational intervention for family caregivers [Hudson et al., 2005] provides family members with a manual, supports them through home visits and telephone calls, and instructs them about self-care and finding meaning.

\subsubsection{Existential Behavioral Therapy for Relatives}

Existential Behavioral Therapy for relatives (EBT) [Fegg et al., 2013] is a combination of mindfulness-based behavioral therapy with existentially oriented psychotherapy focused on mindfulness and acceptance, orientation to values, as well as sources of meaning and resource enhancement [Fegg et al., 2013; Fegg, 2016]. Six group sessions combine psychoeducational elements, group discussions, and experiential approaches: (1) becoming acquainted and introduction into mindfulness; (2) death, bereavement and mindfulness; (3) activating resources and finding meaning; (4) self-care and stress management; (5) personal values for (re-)orientation; (6) saying goodbye and new steps. The relatives also receive a CD with mindfulness exercises for daily practice.

\section{Outlook}

The spectrum of psychological and psychotherapeutic approaches makes a valuable contribution to enhancing the quality of life of patients and relatives in palliative care. Even though appropriate structures for needs-based care of palliative patients in Germany have not yet been established, there is nevertheless a clear trend in this direction. The incorporation of psychological and psychotherapeutic work into palliative care need not only be achieved through the inclusion of psychotherapists in palliative care teams. Practicing psychotherapists may become members of palliative networks on their own initia- 
tive by, for example, visiting quality circles, offering cooperation with outpatient palliative care teams and with hospitals, or participating on a voluntary basis in ethics committees.

"Regardless of whether one works as a practitioner, an educator, or a clinical researcher designing and evaluating treatments, the field of palliative care offers unparalleled opportunities to change lives for the better. Moreover, by helping seriously ill patients and their families find connection and healing in the midst of medical suffering, we ourselves are privileged to find deeper meaning in our own lives through these powerful and inspiring human encounters" [Kasl-Godley et al., 2014, p. 372].

\section{Statement of Ethics}

There are no ethical conflicts in connection with this work.

\section{Disclosure Statement}

The authors hereby declare that they have no conflicts of interest with regard to the manuscript.

\section{References}

Andrade C. Ketamine for Depression, 4: In What Dose, at What Rate, by What Route, for How Long, and at What Frequency? J Clin Psychiatry. 2017 Jul;78(7):e852-7.

Bausewein C. Bislang unterschätzt. Palliativmedizin für Nicht-Tumorpatienten. Klinikarzt. 2005;34(01/02):19-23.

Becker G, Blum HE. "Medical Futility”: Der Arzt im Spannungsfeld von Behandlungsauftrag und Behandlungsbegrenzung. Dtsch Med Wochenschr. 2004 Jul;129(31-32):1694-7.

Berthold D, Gramm J, Gaspar M, Sibelius U, editors. Psychotherapeutische Perspektiven am Lebensende. Göttingen: Vandenhoeck \& Ruprecht; 2017.

Berthold D, Gramm J. Transferarbeit: Psychotherapeutische Interventionen am Lebensende. PiD - Psychother Dialog. 2019;20(01): $32-6$.

Berufsverband Deutscher Psychologinnen und Psychologen (BDP), editor. Berufsbild Psychologie. Psychologische Tätigkeitsfelder [Internet]. 2016 [cited 2018 Aug 1]. Available from: https://www.bdp-verband.de/bdp/archiv/berufsbild-psychologie.pdf

Block SD. Psychological issues in end-of-life care. J Palliat Med. 2006 Jun;9(3):751-72.

Block SD; ACP-ASIM End-of-Life Care Consensus Panel. American College of Physicians American Society of Internal Medicine. Assessing and managing depression in the terminally ill patient. Ann Intern Med. 2000 Feb; 132(3):209-18.

Breitbart W, Gibson C, Poppito SR, Berg A. Psychotherapeutic interventions at the end of life: a focus on meaning and spirituality. Can J Psychiatry. 2004 Jun;49(6):366-72.

Breitbart W, Pessin H, Rosenfeld B, Applebaum AJ, Lichtenthal WG, Li Y, et al. Individual meaning-centered psychotherapy for the treatment of psychological and existential distress: A randomized controlled trial in patients with advanced cancer. Cancer. 2018 Aug;124(15):3231-9.

Breitbart W, Poppito S, Rosenfeld B, Vickers AJ Li Y, Abbey J, et al. Pilot randomized controlled trial of individual meaning-centered psychotherapy for patients with advanced cancer. J Clin Oncol. 2012 Apr;30(12):1304-

Psychotherapeutic Work in Palliative Care
Breitbart W, Rosenfeld B, Gibson C, Pessin H, Poppito S, Nelson C, et al. Meaning-centered group psychotherapy for patients with advanced cancer: a pilot randomized controlled trial. Psychooncology. 2010 Jan;19(1):21-8.

Chochinov HM, Hack T, Hassard T, Kristjanson LJ, McClement S, Harlos M. Dignity therapy: a novel psychotherapeutic intervention for patients near the end of life. J Clin Oncol. 2005 Aug;23(24):5520-5.

Chochinov HM. Dignity-conserving care-a new model for palliative care: helping the patient feel valued. JAMA. 2002 May;287(17):225360 .

Chochinov HM. Würdezentrierte Therapie: was bleibt - Erinnerungen am Ende des Lebens. Göttingen, Bristol, CT: Vandenhoeck \& Ruprecht; 2017.

Clarke DM, Kissane DW. Demoralization: its phenomenology and importance. Aust N Z J Psychiatry. 2002 Dec;36(6):733-42.

Deutsche Gesellschaft für Palliativmedizin. Palliativmedizinisches Basisassessment (PBA) [Internet]. 2016 [cited 2019 Sep 3]. Available from: https://www.dgpalliativmedizin.de/images/Palliativmedizinisches_Basisassessment_2016_überarb_2018.pdf

Endicott J. Measurement of depression in patients with cancer. Cancer. 1984 May;53(10 Suppl): 2243-9.

Fegg M. Zusammenfassende Ergebnisse zur Existenziell Behavioralen Therapie (EBT) für Angehörige von Palliativpatienten. Palliativmedizin. 2016;17(02):76-82.

Fegg MJ, Brandstätter M, Kögler M, Hauke G, Rechenberg-Winter P, Fensterer V, et al. Existential behavioural therapy for informal caregivers of palliative patients: a randomised controlled trial. Psychooncology. 2013 Sep; 22(9):2079-86.

Ferris FD, Balfour HM, Bowen K, Farley J, Hardwick $\mathrm{M}$, Lamontagne $\mathrm{C}$, et al. A model to guide patient and family care: based on nationally accepted principles and norms of practice. J Pain Symptom Manage. 2002 Aug; 24(2):106-23.

Frankl VE. ... trotzdem Ja zum Leben sagen: Ein Psychologe erlebt das Konzentrationslager. 29. Aufl., ungekürzte Ausg. München: Deutscher Taschenbuch-Verlag; 2008.
Grande G, Rowland C, van den Berg B, Hanratty B. Psychological morbidity and general health among family caregivers during end-of-life cancer care: A retrospective census survey. Palliat Med. 2018 Dec;32(10):1605-14.

Harding R, Leam C, Pearce A, Taylor E, Higginson IJ. A multi-professional short-term group intervention for informal caregivers of patients using a home palliative care service. J Palliat Care. 2002;18(4):275-81.

Heidenreich T, Michalak J, editors. Die "dritte Welle" der Verhaltenstherapie: Grundlagen und Praxis. 1st ed. Weinheim, Basel: Beltz; 2013.

Heidenreich T, Michalak J, Eifert G. Balance von Veränderung und achtsamer Akzeptanz: Die dritte Welle der Verhaltenstherapie. Psychother Psych Med. 2007;57(12):475-86.

Henriksson A, Andershed B. A support group programme for relatives during the late palliative phase. Int J Palliat Nurs. 2007 Apr; 13(4):175-83

Hudson PL, Aranda S, Hayman-White K. A psycho-educational intervention for family caregivers of patients receiving palliative care: a randomized controlled trial. J Pain Symptom Manage. 2005 Oct;30(4):329-41.

Kasl-Godley JE, King DA, Quill TE. Opportunities for psychologists in palliative care: working with patients and families across the disease continuum. Am Psychol. 2014 May-Jun; 69(4):364-76

Kern M, Grammatico D, Ostgathe E. "Was brauchen Menschen, die ihre schwerstkranken und sterbenden Angehörigen zu Hause versorgen?" - Ein Projekt von ALPHA Rheinland mit Unterstützung des Ministeriums für Arbeit, Gesundheit und Soziales des Landes Nordrhein-Westfalen [Internet]. Bonn: ALPHA-Rheinland; 2009 [cited 2017 Dec 10]. Available from: https://alpha-nrw.de/wpcontent/uploads/2014/07/was-brauchenmenschen.pdf

Kissane DW, Bloch S, Smith GC, Miach P, Clarke DM, Ikin J, et al. Cognitive-existential group psychotherapy for women with primary breast cancer: a randomised controlled trial. Psychooncology. 2003 Sep;12(6):532-46. 
Kissane DW, McKenzie M, Bloch S, Moskowitz C, McKenzie DP, O'Neill I. Family focused grief therapy: a randomized, controlled trial in palliative care and bereavement. Am J Psychiatry. 2006 Jul;163(7):1208-18.

Kröger F, Altmeyer S, Hendrischke A. Systemische Familienmedizin. KONTEXT. 2002; 33(4):267-87.

Kwak J, Salmon JR, Acquaviva KD, Brandt K, Egan KA. Benefits of training family caregivers on experiences of closure during end-oflife care. J Pain Symptom Manage. 2007 Apr; 33(4):434-45.

Leitlinienprogramm Onkologie (Deutsche Krebsgesellschaft, Deutsche Krebshilfe, AWMF), editor. Palliativmedizin für Patienten mit einer nicht heilbaren Krebserkrankung, Langversion 1.0 [Internet]. 2015 [cited 2018 Aug 1]. Available from: http://leitlinienprogrammonkologie.de/Palliativmedizin.80.0.html

Lo C, Hales S, Jung J, Chiu A, Panday T, Rydall A, et al. Managing Cancer And Living Meaningfully (CALM): phase 2 trial of a brief individual psychotherapy for patients with advanced cancer. Palliat Med. 2014 Mar;28(3):234-42.

Macleod AD. Methylphenidate in terminal depression. J Pain Symptom Manage. 1998 Sep; 16(3):193-8.

Martínez M, Arantzamendi M, Belar A, Carrasco JM, Carvajal A, Rullán M, et al. 'Dignity therapy', a promising intervention in palliative care: A comprehensive systematic literature review. Palliat Med. 2017 Jun;31(6):492-509.

Maugham WS. Sheppey. London: Heinemann; 1933.

Mehnert A, Vehling S, Höcker A, Lehmann C, Koch U. Demoralization and depression in patients with advanced cancer: validation of the German version of the demoralization scale. J Pain Symptom Manage. 2011 Nov: 42(5): $768-76$

Mehnert A. Psychotherapie in der palliativen Versorgung. Psychother Psychosom Med Psychol. 2015 Sep;65(9-10):387-96.

Meran JG. Lebensqualität, Aussichtslosigkeit und Therapiebegrenzung. Imago Hominis. 2003; 10:19-28.

Miller K, Massie MJ. Depressive Disorders. In: Holland JC, Breitbart WS, Jacobsen PB, Loscalzo MJ, McCorkle R, Butow PN, editors. Psycho-oncology. 3rd ed. Oxford, New York: Oxford University Press; 2015. pp. 311-8.

Mitchell AJ, Chan M, Bhatti H, Halton M, Grassi L, Johansen C, et al. Prevalence of depression, anxiety, and adjustment disorder in oncological, haematological, and palliative-care settings: a meta-analysis of 94 interview-based studies. Lancet Oncol. 2011 Feb;12(2):16074 .
Monforte-Royo C, Villavicencio-Chávez C, Tomás-Sábado J, Mahtani-Chugani V, Balaguer A. What lies behind the wish to hasten death? A systematic review and meta-ethnography from the perspective of patients. PLoS One. 2012;7(5):e37117.

Münch U, Gramm J, Berthold D. Mehr als Psychotherapie. Psychologisches Arbeiten in Palliative Care. PiD - Psychother Dialog. 2016; $17(01): 81-5$

Münch U, Gramm J, Jentschke E, Mai S. Palliativpsychologie - Ist eine Approbation wirklich notwendig? Palliativmedizin. 2015;16(05): 191-191

Ohnsorge K, Gudat H, Rehmann-Sutter C. Intentions in wishes to die: analysis and a typology - A report of 30 qualitative case studies of terminally ill cancer patients in palliative care. Psychooncology. 2014 Sep;23(9):1021-6.

Preisler M, Goerling U. Angehörige von an Krebs erkrankten Menschen. Onkologe. 2016;22(5): 336-41.

Prigerson HG, Bierhals AJ, Kasl SV, Reynolds CF 3rd, Shear MK, Newsom JT, et al. Complicated grief as a disorder distinct from bereavement-related depression and anxiety: a replication study. Am J Psychiatry. 1996 Nov; 153(11):1484-6.

Robinson S, Kissane DW, Brooker J, Burney S. A systematic review of the demoralization syndrome in individuals with progressive disease and cancer: a decade of research. J Pain Symptom Manage. 2015 Mar;49(3):595-610.

Röhrle B, Caspar F, Schlottke PF, editors. Lehrbuch der klinisch-psychologischen Diagnostik. 1st ed. Stuttgart: Kohlhammer; 2008.

Sauer T, Weiske K. Angewandte Ethik in der Intensivmedizin: Zwischen medizinischer Indikation und Patientenwille. In: Eckart J, Weigand MA, Briegel J, editors. Intensivmedizin (Kompendium und Repetitorium zur interdisziplinären Weiter- und Fortbildung). Landsberg: ecomed Medizin; im Druck.

Schneider KJ, Krug OT. Existential-humanistic therapy. 1st ed. Washington (DC): American Psychological Association; 2010

Schneiderman LJ, Jecker NS, Jonsen AR. Medical futility: its meaning and ethical implications. Ann Intern Med. 1990 Jun;112(12):949-54.

Schulze W. Hypnose und Hypnotherapie in der Palliativmedizin - Symptombehandlung und spirituelle Begleitung. Palliativmedizin. 2013; 14(02):59-72.
Schulz-Kindermann F, Koch U, Berger H, Hoffmann P, Huse-Kleinstoll G, Lang K, et al. Psychoonkologie: Grundlagen und psychotherapeutische Praxis. 1st ed. Weinheim, Basel: Beltz; 2013.

Sektion Psychologie der DGP, editor. Palliativpsychologie - Berufsbild für Psychologinnen und Psychologen in der Palliativversorgung [Internet]. 2016 [cited 2017 Apr 18]. Available from: https://www.dgpalliativmedizin. de/images/Berufsbild_PalliativpsychologIn_ DGP_2016.pdf

Serfaty M, King M, Nazareth I, Moorey S, Aspden T, Tookman A, et al. Manualised cognitivebehavioural therapy in treating depression in advanced cancer: the CanTalk RCT. Health Technol Assess. 2019 May;23(19):1-106.

Strada EA. Grief, demoralization, and depression: diagnostic challenges and treatment modalities. Prim Psychiatry. 2009 May; 16:7.

Trachsel M, Hermann H, Biller-Andorno N. Urteilsfähigkeit: Ethische Relevanz, konzeptuelle Herausforderung und ärztliche Beurteilung. Schweiz Med Forum. 2014a;14(11): 221-225.

Trachsel M, Krones T, Wild V. Zwangsernährung oder Palliative Care bei chronischer Anorexia nervosa? Behandlungsstrategien aus medizinethischer Sicht. In: Moos T, RehmannSutter C, Schües C, editors. Randzonen des Willens. Frankfurt am Main: Peter Lang; 2016. pp. 173-88.

Trachsel M, Maercker A. Lebensende, Sterben und Tod. 1st ed. Göttingen: Hogrefe; 2016.

Trachsel M, Mitchell C, Biller-Andorno N. Advance directives between respect for patient autonomy and paternalism. In: Lack P, BillerAndorno N, Brauer S, editors. Advance Directives. Dordrecht: Springer Netherlands; 2014b. pp. 169-79.

Trachsel M, Noyon A. Ratgeber Lebensende, Sterben und Tod: Informationen für Betroffene und Angehörige. 1st ed. Göttingen: Hogrefe; 2017.

Willig C, Wirth L. A meta-synthesis of studies of patients' experience of living with terminal cancer. Health Psychol. 2018 Mar;37(3):22837.

World Health Organization, editor. National cancer control programmes: policies and managerial guidelines. 2nd ed. Geneva: World Health Organization; 2002.

Znoj H. Komplizierte Trauer. 2., überarbeitete Auflage. Göttingen: Hogrefe; 2016. 